\title{
ULTIMA REPLICA A LOS COMENTARIOS DE ENRIQUE LLOPIS
}

B. YUN CASALILLA

Universidad de Valladolid

Quiero dar las gracias a Llopis por la atención que me presta de nuevo $\mathrm{y}$, a la vista del tiempo transcurrido, redactar estas breves líneas, para explicar que, pese a su actualización bibliográfica, la situación es la misma. Me limitaré a un solo comentario y a subrayar los acuerdos:

Por un lado, en el punto en que está la cuestión del mercado del trigo, lo obligado es empezar a investigar. Una reserva para hacerlo bien, ya que surge el tema, es la siguiente: Llopis no aclara cuál es la distribución a lo largo del año de los precios que cita y qué ponderación ha aplicado para paliar el efecto de primacía que induce en la media la mayor abundancia de datos de los meses mayores. Me temo que no se ha ponderado y que sus datos responden preferentemente a la situación del mercado en dichos meses, cuando - si no se demuestra lo contrario- hemos de pensar que los precios tienden a igualarse en su máximo anual. Es obligado, pues, que resulte un alto grado de integración y, más importante aquí, que las diferencias entre cada intervalo sean pequeñas, dado que en ese nivel no pueden esperarse grandes cambios. Me pregunto si su análisis no encierra una tautología metodológica. Sea como fuere, debería explicar por qué ahora dice que «el simple mantenimiento de aquella [la volatilidad (sic) del precio], caso de confirmarse, sería por sí mismo revelador de la existencia de algún tipo de transformaciones en el funcionamiento del mercado», mientras que antes, con los mismos datos y pese a considerar también la «agudización de las crisis frumentarias", prefería subrayar que «el proceso de avance en la interrelación de los mercados parece, cuando menos, estancarse desde, aproximadamente, los años sesenta». Estas contradicciones y lecturas, forzadas de los propios datos según la tesis de los demás que se pretenden rebatir, son indicativas de los errores en que se puede caer al iniciar polémicas mal planteadas; hecho éste al que me refería en «De molinos a gigantes...».

Contestaría otras precisiones repitiendo que yo no he atribuido al funcionamiento del mercado en si mismo el atraso de la región, sino una estructura económica y social concreta y al complejo funcionamiento de una red 
comercial suprarregional que no da pie a contrafactuales como los que ahora plantea pero que yo respeto si le son útiles para su investigación; la mía prefiero plantearla de otro modo. Pero prefiero mostrar mi acuerdo dándole la razón en una afirmación que hacía antes de necesitar los datos que ahora le parecen tan precisos: a la vista de sus «numerosas e importantes limitaciones», «parece conveniente $[\ldots]$ la realización de nuevas investigaciones que permitan corroborar o refutar las bipótesis aquí avanzadas». (Todos los subrayados son míos) ${ }^{1}$.

Por otro lado, desde luego que me preocupa la utilidad de los resultados de mi investigación para otros investigadores, pero aún más que se den ideas sesgadas de ellos (y nótese que Llopis lo sigue haciendo al reducir mis argumentos a los relativos al mercado como hecho aislado) para, a la postre. echar de menos parte de los mismos. La obligación de alguien que reseña un libro es hacer críticas, pero también reflejar su contenido y hacer esas críticas respecto a éste. Veamos algunas presuntas carencias:

a) En relación con las cuestiones sobre la «renuncia de la Monarquía» a rescatar las rentas enajenadas a la aristocracia y sus «secuelas» políticas y fiscales, ya me manifesté en 1985; las reitero en el libro y, aunque el término «renuncia» sólo atiende a parte de lo ocurrido, las he analizado en un trabajo que Llopis no tiene en cuenta en su actualizada bibliografía ${ }^{2}$. No sé si

' La tendencia a vender durante «los meses mayores» de las instituciones que estudian es subrayada por los mismos Escrivá y Llopis; asimismo, para la contradictoria interpretación, confróntese con Escrivá y Llopis (1987; las citas textuales en pp. 126 y 128). Considero preferible la búsqueda en los archivos a seguir manipulando los precios de que disponemos, máxime si se trata de precios al por mayor. No obstante, no critico el uso del poco material disponible, sobre todo si se trata de crear hipótesis. Lo que no creo conveniente es que esas hipótesis se exhiban como cálculos definitivos, forzando la interpretación según interese para, además, discrepar tan sólo en algo (el subrayado, ahora, es de Llopis). Quiero pensar -ésa es mi costumbre cuando tengo este tipo de «dudas»- que parte del pro. blema estriba en la falta de adecuación entre los intervalos que Llopis compara y la contradictoria política de liberalización del mercado $\mathrm{y}$, en todo caso, no creo que los pacientes lectores puedan ver muchas diferencias entre mis opiniones y las de Llopis sobre los efectos de esa liberalización en el statu quo. Considero, además, que el estudio de Escrivá y Llopis tiene un valor "neto positivo», pero no me resisto a añadir, ya que recuerda lo que está ocurriendo aquí, que dicho trabajo parte de la "comercial y llamativa" técnica de presentar una tesis maximalista y ambigua que nadie, que yo scpa, ha mantenido para mercados de una misma región geográfica (la de la «nula o casi nula" integración de éstos), con el objeto de arremeter contra ella, utilizando además unos datos que no llegan a medir el grado de integración. Nótese, además, que el trabajo lleva en su título el término «estancamientom en un sentido que -imagino- no interesa ahora retomar a Llopis.

${ }^{2}$ Repito, Llopis debe volver a leer las conclusiones $\left(1987\right.$, p. 643, párrafo $\left.2 .^{\circ}\right)$ y las tesis cxpuestas en 1985, donde se habla de los «procesos frustrados de rescate» de las rentas, o, volviendo al libro, de que la "presión fiscal en aumento es la presión de una monarquía comprometida socialmente, ya que era la de un Estado que había ido enajenando rentas durante la Baja Edad Media en favor de los grandes señores y que, antes de rescatarlas, prefirió (o fue obligado a) buscar fondos a costa de los súbditos pecheros» (1987 a, p. 305). También se dice que «el respeto de la Monarquía a las rentas enajenadas previa- 
la razón del equívoco está en mi incapacidad para presentar los resultados de mi investigación, pero me alegro de que las investigaciones personales de Llopis sobre las relaciones entre aristocracia y monarquía y sus efectos hayan coincidido tan expresivamente con las mías.

b) Lo mismo ocurre con el asunto de los «millones», del control de las oligarquías urbanas sobre el cobro de impuestos y de cómo lo aprovecharon para privatizar tierras públicas. Aunque éste sea un logro de investigaciones anteriores a mi libro y al estudio de Llopis que él cita, es tal mi convencimiento que lo referí en el libro, lo repetí en obras de divulgación y lo he ampliado, no hace mucho, subrayando su importancia para el conjunto del reino, en línea complementaria a la que utilicé en las conclusiones ${ }^{3}$.

c) Es interesante el discurso de Llopis - como el anterior, inexistente en sus antiguas «discrepancias»- sobre la «vía "descentralizada"» en el conjunto de la Corona. Como a los adehesamientos me referí en trabajos que ya casi he olvidado, señalaré que he tratado la generalidad del tema para el conjunto del Valle del Duero ${ }^{4}$, que en el libro se refiere el fenómeno estableciendo las diferencias con respecto a la Tierra de Campos y que, incluso en ésta, se subraya lo suficiente su presencia como para dedicar un epígrafe a las estrategias de formación de grandes patrimonios eclesiásticos a costa de la propiedad campesina o de tierras comunales ${ }^{5}$. Ahora bien, al ver cómo

mente" llevaba a una mayor presión impositiva (p. 395). El tema lo he desarrollado en varias ocasiones, pero véase sobre todo Yun $(1987 \mathrm{~b})$, y para sus efectos indirectos sobre la economia mercantil y artesanal, Y'un (abril de 1989), donde se desarrollan ideas ya contenidas en el libro. Quizá Llopis eche de menos un mayor énfasis, no en los efectos fiscales o en la expansión de la deuda, sino en el mercado de dinero. Pero eso va implícito si se considera la continua alusión a los efectos negativos de los juros y los censos sobre mayorazgos en la actividad productiva (B. Yun, 1987, pp. $248-256$ y 260, entre otras). En todo caso, la diferencia no da para dudas o discrepancias, sino para una línea de reflexión e investigación complementaria.

${ }^{3}$ Si lo que quiere Llopis es poner énfasis en la acción y control de las oligarquias sobre la distribución de impuestos, esto es algo reiterado en mi libro (Yun, 1987 a, pp. 370-378, y. como resultado, en las conclusiones, p. 643, párrafo $\left.3 .^{\circ}\right)$. El tema lo he expuesto con una visión más general en varias ocasiones; omito las más recientes, pero véase $Y$ un $(1986 b$, p. 49). No obstante, la idea es tan vieja que no quisiera dar la impresión de que me atribuyo su autoría. Véanse C. Viñas Mey (1941) o F. Ruis Martín (1959), entre otros. Si lo que Llopis echa de menos es la conexión entre millones y privatización de tierras, hay que decir que esto fue poco frecuente en la Tierra de Campos, pero que en el trabajo se refieren los estudios que en su día lo demostraron con datos de primera mano: A. García Sanz (1980) y, puesto que abre el ámbito geográfico, J. M. de Bernardo Ares (1981) o A. M. Bernal (1978). Y, por cierto, basta leer despacio para ver la advertencia al lector de que, por imposición del área estudiada, el análisis se hace edesde la perspectiva de unas oligarquías de segunda fila», reseñándose también que, no obstante, «reproducen muchos de los comportamientos de las oligarquias urbanas" (p. 371).

B. Yun (1986, p. 59, y 1987 a. p. 313).

"Véanse referencias a las revisiones de «foros» o a los abusos por la explotación de montes en las pp. 281 y 282 . Presiones hasta causar la despoblación de algunas villas, en p. 312, matizándose, lógicamente, que ése no fue aquí el expediente más útil para salvar 
pasan inadvertidas estas cuestiones, no me arrepiento de haber enfatizado la «vía "centralizada"», porque así se ha resaltado una cuestión a veces relegada en excelentes estudios.

Espero que la paciencia de los editores de la Revista de Historia EconóMICA y de sus lectores interesados, si los hay, sirva para que los historiadores leamos con más cuidado y sosiego (el esfuerzo, desde luego, se lo reconozco a Enrique Llopis) y planteemos, en el futuro, las polémicas más acertadamente.

\section{BIBLIOGRAFIA}

Bernal, A. M. (1978): «Haciendas locales y tierras de propios: funcionalidad económica de los patrimonios municipales (siglos XII-XIX)», en Hacienda Pública Española, núm. 55, pp. $285-312$.

Bernardo Ares, J. M. (1981): «Presión fiscal y bienes de propios a principios del siglo XVII», en Axarquia, núm. 2, pp. 129.142.

Escrivá, J. L., y Llopis AGElán, E. (1987): «La integración del mercado triguero en la Castilla la Vieja-Ieón del Antiguo Régimen: Avance y estancamientom, en Hacienda Pública Española, núms. 108-109, pp. 117.131.

García Sanz, A. (1980): «Bienes y derechos comunales y el proceso de su privatización en Castilla durante los siglos xvi y xvir: el caso de Tierras de Segovia", en Hispania, núm. 144.

Ruiz Martín, F. (1959): «Procedimientos crediticios para la recaudación de los tributos fiscales en las ciudades castellanas durante los siglos xvi al xvir: el caso de Valladolid», en Actas de Dinero y Crédito. I Coloquio Internacional de Historia Económica, Madrid, Ed. Banco Urquijo, pp. 37-47.

Viñas MeY, C. (1941): El problema de la tierra en la España de los siglos XVI-XVII, Madrid, CSIC.

Yun Casalilla, B. (1985): «Aristocracia, señorío y crecimiento económico en Castilla: algunas reflexiones a partir de los Pimentel y los Enríquez (siglos XVI y XVII)", en REvista de Historia EConómic^, núm. 3, pp. 443-472.

- (1986): «Crisis económica e inmovilismo de las estructuras sociales», en Historia de Castilla y León, VII: La época de la decadencia (siglo XVII), Valladolid, Ed. Ambito.

- (1987 a): Sobre la transición al capitalismo en Castilla. Economía y Sociedad en Tierra de Campos (1500-1830), Salamanca, Ed. Junta de Castilla y León.

- $(1987 b)$ : "Carlos V y la aristocracia. Poder, crédito y economía en Castilla», en Hacienda Pública Española, núms. 108-109.

- (abril 1989): «Estado, estructuras sociales y cambio económico entre 1550 y 1630 en Castilla la Vieja y León», en Meeting of the Society for Spanish Studies, St. Louis, Missouri (presentado para su publicación en la Revista dE Historia EconómiCa).

la «crisis de la aristocracia», y haciendo ver que el caso fue más fuerte en otras zonas castellanas. Aún más énfasis en la "vía "descentralizada" ", en pp. 124 (especialmente) y ss. Una contraposición de ambas, sin detrimento de ésta, en p. 396. Procesos de apropiación de baldíos a través de la compra por instituciones eclesiásticas, en pp. 300 y ss. Todo un epígrafe que subraya la «vía "descentralizada"» y las estrategias de ampliación de la propiedad de las instituciones eclesiásticas, en pp. 330-370. Y todo ello, pese a la advertencia a los lectores de que hay cuestiones como la «distribución exacta de la propiedad [...] que de forma indiscutible se refieren exclusivamente a la Tierra de Campos" (p. 18), y que salvan a mi estudio de pretensiones generalizadoras en este punto. La existencia de estructuras de renta señorial distintas, que pudieran haber condicionado las estrategias señoriales y que son predominantes en otras regiones, se expresa también para esta comarca en pp. 333 y 336, y me ahorro la cita de trabajos en que se han estudiado justamente algunas de esas estrategias. 